\title{
Levels of toothache-related interests of Google and YouTube users from developed and developing countries over time
}

\author{
Matheus Lotto ${ }^{\text {Equal first author, }{ }^{1}, \text { Patricia EA Aguirre }}{ }^{1}$, Anna P Strieder $^{1}$, Agnes FP Cruvinel $^{2}$, Thiago Cruvinel $^{\text {Corresp. Equal first }}$ \\ author, 1 \\ 1 Department of Pediatric Dentistry, Orthodontics and Public Health, University of São Paulo, Bauru School of Dentistry, Bauru, São Paulo, Brazil \\ Discipline of Public Health, School of Medicine, Federal University of Fronteira Sul, Chapecó, Santa Catarina, Brazil \\ Corresponding Author: Thiago Cruvinel \\ Email address: thiagocruvinel@fob.usp.br
}

Background: The preferences of Web users can be influenced by distinct factors of populations. Hence, hypothetically, source-based patterns of health-related Web searches might differ between individuals from developed and developing countries, due to their distinct educational, social, economic, political, cultural, and psychosocialbackgrounds. In this sense, this study aimed to determine the trends of toothache-related searches performed on Google Search and YouTube, regarding differences between developed and developing countries.

Methods: This retrospective longitudinal study analyzed computational metadata on toothache-related interests of Internet users. Google Trends was accessed to obtain the monthly variation of relative search volume (RSV) of the topic "Toothache-Disease" on Google (G) and YouTube (YT) through 2008 to 2017. Autocorrelation and partial autocorrelation plots, ARIMA models, Kruskal-Wallis, Dunn's and T tests were performed for evaluating trends, 12-month forecasts and the differences of annual ratios of YT/G searches between developed and developing countries, respectively $(P<0.05)$.

Results: Uptrends of RSVs were observed in both country groups over time, although 12-month forecasts tended to plateau.The volumes of searches were higher in developed countries in comparison to developing ones; however, this difference was not observed regarding Google searches performed between 2016 and 2017. Independently of country groups, the ratios YT/G remained relatively constant throughout the period, indicating a greater interest in toothache-related information available on Google.

Conclusion: In conclusion, toothache-related searches from Google and YouTube increased during the last decade. The preferences of Web users seemed to be influenced by the differences between developed and developing countries, such as the availability and penetration of the Internet, and education levels. 


\section{Levels of toothache-related interests of Google and YouTube users 2 from developed and developing countries over time}

3

4 Matheus Lotto ${ }^{1}$, Patricia Estefania Ayala Aguirre ${ }^{2}$, Anna Paola Strieder ${ }^{3}$, Agnes Fátima Pereira

5 Cruvinel $^{4}$, Thiago Cruvinel ${ }^{5}$

6

$7{ }^{1}$ Department of Pediatric Dentistry, Orthodontics and Public Health, Bauru School of Dentistry, 8 University of São Paulo, Bauru, São Paulo, Brazil

92 Department of Pediatric Dentistry, Orthodontics and Public Health, Bauru School of Dentistry, 10 University of São Paulo, Bauru, São Paulo, Brazil

$11{ }^{3}$ Department of Pediatric Dentistry, Orthodontics and Public Health, Bauru School of Dentistry, 12 University of São Paulo, Bauru, São Paulo, Brazil

$13{ }^{4}$ Discipline of Public Health, School of Medicine, Federal University of Fronteira Sul, Chapecó, Santa 14 Catarina, Brazil

$15{ }^{5}$ Department of Pediatric Dentistry, Orthodontics and Public Health, Bauru School of Dentistry, 16 University of São Paulo, Bauru, São Paulo, Brazil

17

18

19

20

21

22

23

24

25

26

27

28

29

30

31

32

33

34

35

36
Corresponding Author:

Thiago Cruvinel ${ }^{5}$

Al. Dr. Octávio Pinheiro Brisolla, 9-75, Vila Universitária, Bauru, São Paulo, 17012-901, Brazil

Email address: thiagocruvinel@fob.usp.br

\section{4}

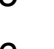

27




\section{Abstract}

38 Background: The preferences of Web users can be influenced by distinct factors of populations. Hence, hypothetically, source-based patterns of health-related Web searches might differ between individuals from developed and developing countries, due to their distinct educational, social, economic, political, cultural, and psychosocial backgrounds. In this sense, this study aimed to determine the trends of toothache-related searches performed on Google Search and YouTube, regarding differences between developed and developing countries. Methods: This retrospective longitudinal study analyzed computational metadata on toothacherelated interests of Internet users. Google Trends was accessed to obtain the monthly variation of relative search volume (RSV) of the topic "Toothache-Disease" on Google (G) and YouTube (YT) through 2008 to 2017. Autocorrelation and partial autocorrelation plots, ARIMA models, Kruskal-Wallis, Dunn's and T tests were performed for evaluating trends, 12-month forecasts and the differences of annual ratios of YT/G searches between developed and developing countries, respectively $(P<0.05)$.

Results: Uptrends of RSVs were observed in both country groups over time, although 12-month forecasts tended to plateau. The volumes of searches were higher in developed countries in comparison to developing ones; however, this difference was not observed regarding Google searches performed between 2016 and 2017. Independently of country groups, the ratios YT/G remained relatively constant throughout the period, indicating a greater interest in toothacherelated information available on Google.

Conclusion: In conclusion, toothache-related searches from Google and YouTube increased during the last decade. The preferences of Web users seemed to be influenced by the differences between developed and developing countries, such as the availability and penetration of the Internet, and education levels.

\section{Introduction}

The spreading of information and communication technologies (ICTs) empowered individuals to obtain health knowledge and decide about their own conditions, including searches for alternatives to their demands. It is noteworthy that most Internet users are interested in healthrelated topics retrieved by digital platforms (Aguirre et al., 2018), such as search engine tools, video-sharing websites, and social media (Hansen et al., 2018; Atkinson, Saperstein \& Pleis, 2009).

In this context, we previously demonstrated a great activity of Internet users searching for toothache-related issues, with the aim of achieving self-resolution of dental pain through the adoption of alternative methods, such as painkillers and home remedies (Cohen et al., 2009; Ahlwardt et al., 2014; Lotto et al., 2017). These behaviors tend to be exacerbated over the years, since oral diseases and their painful symptoms continue to be highly prevalent worldwide (Pitts et al., 2011; Cohen et al., 2008; Peres et al. 2010), especially among social deprived groups (Santiago, Valença, \& Vettore, 2013; da Cunha et al., 2017). 
76 The preferences of Web health seekers can be influenced by distinct factors, such as the ability 77 of people in obtaining, processing, and understanding information adequately (Levin-Zamir \&

78 Bertschi, 2018). For instance, participants of Web-based computer-tailored preventive programs 79 preferred videos instead of reading materials, because their usefulness, involvement, and 80 attractiveness (Walthouwer et al., 2015). In a similar way, people expect to solve their questions 81 finding adequate health contents in videos online (Azer et al., 2013; Madathil et al., 2015; Sahin 82 et al., 2018). YouTube presents the highest popularity among streaming services, achieving 1.5 83 billion users and more than 2 billion views per day globally (Statista, 2018).

84 In this sense, hypothetically, source-based patterns of health-related Web searches might differ 85 between individuals from developed and developing countries, due to their social, economic, 86 political, cultural, and psychosocial backgrounds (Cruvinel et al., 2017; Cruvinel et al., 2018; 87 Cruvinel et al., 2019). To our knowledge, there is no evidence comparing the volume of oral health-related searches obtained from search engines and video platforms in different populations. This evidence can contribute to the planning and implementation of educational strategies, guiding the production of contents according to the characteristics of audiences, to minimize the consumption of misinformation. Therefore, this study aimed to determine the trends of toothache-related searches performed by Google and YouTube users, regarding developed and developing countries. The null hypothesis was stated as the levels of toothacherelated interests would have no differences between country groups over time $\left(H_{0}\right)$.

\section{Materials \& Methods}

\section{Study design}

This retrospective longitudinal study analyzed computational metadata on toothache-related interests of Internet users. Google Trends was accessed to obtain the monthly variation of the relative search volume (RSV) of the topic "Toothache-Disease", considering Google Search (G) and YouTube (YT) from developed and developing countries through 2008 to 2017. The trends, 12-month forecasts and annual ratios of $\mathrm{YT} / \mathrm{G}$ searches were determined and compared between both country groups.

\section{Country groups}

Ten countries were divided into two groups, according to their socioeconomic development levels. The inclusion criteria were defined as countries from different continents and hemispheres with more than 15 million inhabitants and $>50 \%$ of Internet penetration (World Bank Group, 2018). To avoid selection bias for the comparison of countries, both groups were statistically similar in relation to the burden of untreated dental caries in permanent teeth measured by the disability-adjusted life years (DALYs) (Institute for Health Metrics and Evaluation, 2018) (Table 1). Developed countries were composed by Australia, Chile, Japan, United Kingdom, and United States, while developing countries were composed by Brazil, Mexico, Russia, Saudi Arabia and South Africa. This classification is in accordance with The 
116 Relative search volume (RSV)

117 The platform Google Trends was used for data collection. It depicts results of the monthly

118 variation of RSVs of specific queries, ranging from 0 to 100 . These values represent the

119 normalized ratio of search volume of a particular keyword by the overall searches detected in a

120 given time, considering the maximum value of the curve as RSV=100. Also, results presented by

121 Google Trends can be filtered by location, time, category, and source of information, with the

122 availability of determination of RSVs of popular issues by topics related to predefined and

123 automatic algorithms.

124 On August 27, 2018, the volume of data related to the topic "Toothache-Disease" - an automatic

125 algorithm that combines all keywords, sentences and terms related to this issue - was determined

126 according to the activity of Google and YouTube users, through January 2008 to December 2017.

127

128

Data analysis

129

Data were analyzed with the Statistical Package for Social Sciences (version 22.0; SPSS,

130 Chicago, IL, USA), as follows:

131 1. RSV trends: the curves of observed RSV values were analyzed heuristically. The trends of

132 toothache-related time series were also checked by autocorrelation (ACF) and partial

133 autocorrelation (PACF) plots.

134 2. Comparisons between time series: since fitted values of Google- and YouTube-based RSVs

135 were normally and homogeneously distributed (Kolmogorov-Smirnov and Levene tests), T

136 independent test was applied to compare the curves and their segments from developed and

137 developing countries.

138 3. Forecasting models: data collected until December 2017 were applied to construct 12-month

139 forecasts for toothache-related RSV values. For that, autoregressive integrated moving average

140 (ARIMA) models were chosen by the lowest values of normalized Bayesian information criteria

141 (Normalized BIC), among curves without a significant residual autocorrelation (Ljung-Box test).

142 4. Comparison of ratios YT/G: since these values were not normally and homogeneously

143 distributed (Kolmogorov-Smirnov and Levene tests), ratios were compared using Kruskal-Wallis

144 and Dunn's test, considering country groups and different years.

145 For all statistical analysis, $P$ values $<0.05$ were considered significant.

146

\section{Results}

148 RSV trends

149 Heuristically, RSVs for Google and YouTube increased in both country groups over time (Fig.

150 1); however, it was not possible to establish conclusive trends using ACF and PACF analyses

151 (Fig. 2). A significant negative autocorrelation was detected in Google searches from developed

152 countries (lag 2), while a significant positive autocorrelation was detected in Google searches

153 from developing countries (lag 1).

154

155

Comparisons between time series

Peer] reviewing PDF | (2019:02:35388:1:1:NEW 25 Jul 2019) 
156 The percentages of increments of Google- and YouTube-based searches were respectively $157 \quad 146.9 \%$ and $156.1 \%$ for developed countries, and $288 \%$ and $273.3 \%$ for developing countries.

158 The means of Google-based searches on toothache were significantly higher than those of 159 YouTube-based searches in developed (61.74 vs. 16.01) and developing countries (46.79 vs. 160 10.91). Comparing the last five years, these significant differences were maintained only in 161 relation to Google-based searches; however, search volumes were similar between both groups 162 in the last two years, whereas YouTube-based searches were significantly higher in developed 163 countries in 2017 (Table 2).

164

Forecasting models

166

167

168

169

170

171

172

173

174

175

176

177

178

179

180

181

182

183

184

185

186

187

188

189

190

191

192

193

194

195

Table 3 summarizes adequacy measures and parameter estimation of forecasting models for toothache-related RSV values. The excellent adequacy of ARIMA models was demonstrated by low values of normalized BIC (2.42-4.19). The curves of observed and fitted values of ARIMA models are showed in Fig. 3. Twelve-month forecasts tended to plateau, independently of the source of information and country groups.

Ratio between Google and YouTube searches (YT/G)

The volume of Google-based searches was higher than that observed in YouTube between 2008 and 2017. Additionally, there was no statistical difference between the ratios of YT/G searches over time, considering both country groups (Fig. 4).

\section{Discussion}

These findings indicate the increment of volumes of toothache-related searches through 20082017, with differences between developed and developing countries. The volumes of Googleand YouTube-based searches were larger in developed countries, with differences decreasing for Google and increasing for YouTube in last years. Also, the ratios YT/G remained constant over the years, independently of country groups. To our knowledge, this is the first study that compared the interests of Google and YouTube users in toothache-related information, regarding the socioeconomic development levels of countries.

The accentuated growth of toothache-related interests observed in developing countries in the last years can be explained by the notorious increase of their Internet penetration. This phenomenon can be explained by three main factors: the rapid expansion of digital infrastructure, the popularization of gadgets, and the decrease of Web access costs (World Bank Group, 2018; Aliance for Afordable Internet, 2018). In this sense, an interesting set of results was detected, as follows: i) the volumes of Google-based RSVs were maintained significantly higher in developed countries only until 2015; ii) distinctly, the volumes of YouTube-based searches were similar between both groups from 2013 to 2016; iii) in 2017, YouTube-based searches returned to be significantly higher in developed countries, as noted in the whole period of time (2008-2017). These findings may be related to the late digital inclusion of developing countries, since netizens are more prone to access health information for solving their own conditions in comparison to 
196

197

198

199

200

201

202

203

204

205

206

207

208

209

210

211

212

213

214

215

216

217

218

219

220

221

222

223

224

225

226

227

228

229

230

231

232

233

234

235

new Internet users (Perrin \& Bertoni, 2017). In a second time, the lower level of education can influence the preferences of users in relation to Web media, favoring the consumption of videos instead of reading materials (Walthouwer et al., 2015). This pattern could explain the similarities of YouTube-based searches between both country groups. Finally, a new YouTube-based difference found in the last year of analysis can be related to the mobile access to the Internet, which differs in diffusion, cost and quality according to countries (Fox \& Duggan, 2013). The growing interest in toothache observed in both platforms can be justified by the negative impact of untreated dental caries in permanent teeth on the quality of life of individuals (Institute for Health Metrics and Evaluation, 2018). This behavior is related to the self-resolution of oral symptoms (Cruvinel et al., 2019), motivated by barriers for dental treatment, such as high expenses of private services and insufficient offering of public attendance (Dhama et al., 2016). In these conditions, the use of YouTube as a source of health information is justified by the rapid increase of its market share, with approximately $+17 \%$ in audience until 2021 (Statista, 2018), and by the enhancement of learning that it provides for Web users (Clifton \& Mann, 2011; Barry et al., 2016; Shatto \& Erwin, 2017).

Some methodological aspects deserve more clarification. Data were collected from Google Trends because it enables the comparison of search volumes of specific topics between Google and YouTube, both leaders in their markets (Net Market Share, 2018). Also, the selection criteria of countries considered a minimum population and Internet penetration to provide an adequate amount of data for statistical analysis. For that, the country groups presented similar DALYs indices, avoiding the influence of the burden of dental caries on the interpretation of these results. Moreover, the geographic diversity of countries intended to minimize the influence of social, cultural and economic factors during these analyses.

These results need to be interpreted with caution. These data are referring exclusively to the activity and behavior of users from two Web platforms, not considering the information of other search engine tools. Additionally, it is not possible to associate socioeconomic characteristics of particular users with their behaviors, since their searches are performed anonymously. Also, this approach can overestimate the activity of netizens, because the impossibility of exclusion of duplicate searches performed by a same person in two or more distinct devices. Finally, although behaviors of users lead us to believe that growing searches are related to self-resolution of oral diseases, it is not possible to state that this aspect always translates into the use of remedies or the adoption of alternative measures.

\section{Conclusions}

In conclusion, toothache-related searches performed on Google and YouTube increased indistinctly during the last decade. The media preferences of users seemed to be influenced by the differences in the education levels, spreading and availability of the Internet found in developed and developing countries. Therefore, the hypothesis $H_{0}$ was rejected. Indeed, the analysis of these computational-based data can subsidize the diffusion of health educational programs and campaigns, empowering people in making correct and autonomous oral health- 
236 related choices. This strategy is important to minimize damages caused by the ineffective self237 management of toothache, which can lead to dental loss and systemic complications.

238

239

240

241

242

243

244

245

246

247

248

249

250

251

252

253

254

255

256

257

258

259

260

261

262

263

264

265

266

267

268

269

270

271

\section{Acknowledgements}

None.

\section{References}

Aguirre PE, Coelho M, Oliveira TM, Rios D, Cruvinel AF, Cruvinel T. 2018. What can Google inform us about people's interests regarding dental caries in different populations? Caries Research 52:177-188. DOI: 10.1159/000485107.

Ahlwardt K, Heaivilin N, Gibbs J, Page J, Gerbert B, Tsoh JY. 2014. Tweeting about pain: comparing self-reported toothache experiences with those of backaches, earaches and headaches. Journal of the American Dental Association 145:737-743. DOI: 10.14219/jada.2014.30.

Aliance for Afordable Internet. 2018. Mobile broadband data costs. Available at https://a4ai.org/mobile-broadband-pricing-data/ (accessed 05 December 2018).

Atkinson NL, Saperstein SL, Pleis J. 2009. Using the internet for health-related activities: findings from a national probability sample. Journal of Medical Internet Research 11:e4. DOI :10.2196/jmir.1035.

Azer SA, Algrain HA, AlKhelaif RA, AlEshaiwi SM. 2013. Evaluation of the educational value of YouTube videos about physical examination of the cardiovascular and respiratory systems. Journal of Medical Internet Research 15:e241. DOI: 10.2196/jmir.2728.

Barry DS, Marzouk F, Chulak-Oglu K, Bennett D, Tierney P, O'Keeffe GW. 2016 Anatomy education for the YouTube generation. Anatomical Sciences Education 9: 90-96. DOI: 10.1002/ase. 1550 .

Clifton A, Mann C. 2011. Can YouTube enhance student nurse learning? Nurse Education Today 31:311-313. DOI: $10.1016 /$ j.nedt.2010.10.004.

Cohen LA, Bonito AJ, Akin DR, Manski RJ, Macek MD, Edwards RR, Cornelius LJ. 2008. Toothache pain: a comparison of visits to physicians, emergency departments and dentists. Journal of the American Dental Association 139:1205-1216. DOI: 10.14219/jada.archive.2008.0336.

Cohen LA, Bonito AJ, Akin DR, Manski RJ, Macek MD, Edwards RR, Cornelius LJ. 2009. Toothache pain: behavioral impact and self-care strategies. Special Care in Dentistry 29:85-95. DOI : 10.1111/j.1754-4505.2008.00068.x.

Cruvinel AFP, Méndez DAC, Oliveira JG, Gutierres E, Lotto M, Machado MAAM, Oliveira TM, Cruvinel T. 2017. The Brazilian version of the 20-item rapid estimate of adult literacy in medicine and dentistry. PeerJ 5:e3744. DOI: 10.7717/peerj.3744. 
272 Cruvinel AFP, Méndez DAC, Chaves GC, Gutierres E, Lotto M, Oliveira TM, Cruvinel T. 2018. 273 The Brazilian validation of a health literacy instrument: the newest vital sign. Acta Odontologica 274 Scandinavica 76:587-594. DOI: 10.1080/00016357.2018.1484511.

275 Cruvinel T, Aguirre PEA, Lotto M, Oliveira TM, Rios D, Cruvinel AF. 2019. Digital behavior 276 surveillance: monitoring dental caries and toothache interests of Google users from developing 277 countries. Oral Diseases 25:339-347. DOI: 10.1111/odi.12986.

278 da Cunha IP, Pereira AC, Frias AC, Vieira V, Meneghim MC, Batista MJ, Cortellazzi KL, 279 Bulgareli JV. 2017. Social vulnerability and factors associated with oral impact on daily 280 performance among adolescents, Health and Quality of Life Outcomes 15:173. DOI:

281 10.1186/s12955-017-0746-1.

282 Dhama K, Patthi B, Singla A, Gupta R, Niraj LK, Ali I, Kumer JK, Prasad M. 2016. Global 283 tourist guide to oral care - a systematic review. Journal of Clinical and Diagnostic Research 284 10:ZE01-ZE4. DOI: 10.7860/JCDR/2016/19438.8408.

285 Fox, S., \& Duggan, M. 2013. Health online 2013. Available at 286 http://www.pewinternet.org/2013/01/15/health-online-2013/ (accessed 05 December 2018)

287 Hansen AH, Broz J, Claudi T, Årsand E. 2018. Relations between the use of electronic health 288 and the use of general practitioner and somatic specialist visits in patients with type 1 diabetes: 289 cross-sectional study. Journal of Medical Internet Research 20:e11322. DOI: 10.2196/11322.

290 Institute for Health Metrics and Evaluation. 2018. Disability-adjusted life years (DALYs). 291 Available at https://vizhub.healthdata.org/gbd-compare/ (accessed 26 September 2018).

292 Levin-Zamir D, Bertschi I. 2018. Media health literacy, ehealth literacy, and the role of the social 293 environment in context. International Journal of Environmental Research and Public Health 294 15:pii. DOI: 10.3390/ijerph15081643.

295 Lotto M, Aguirre PEA, Rios D, Machado MAAM, Cruvinel AFP, Cruvinel T. 2017. Analysis of 296 the interests of Google users on toothache information. PLoS One 12:e186059. DOI:

297 10.1371/journal.pone.0186059.

298 Madathil KC, Rivera-Rodriguez AJ, Greenstein JS, Gramopadhye AK. 2015. Healthcare 299 information on YouTube: a systematic review. Health Informatics Journal 21:173-194. DOI: $30010.1177 / 1460458213512220$.

301 Net Market Share. 2018. Market share statistics for Internet technologies. Available at 302 https://netmarketshare.com (accessed 26 September 2018).

303 Peres MA, Peres KG, Frias AC, Antunes JL. 2010. Contextual and individual assessment of 304 dental pain period prevalence in adolescents: a multilevel approach. BMC Oral Health 10:20. 305 DOI: 10.1186/1472-6831-10-20. 
306 Perrin A, Bertoni N. 2017. First-time internet users: Who they are and what they do when they 307 get online. Available at http://www.pewresearch.org/fact-tank/2017/12/01/first-time-internet308 users-who-they-are-and-what-they-do-when-they-get-online/ (accessed 05 December 2018)

309 Pitts N, Amaechi B, Niederman R, Acevedo AM, Vianna R, Ganss C, Ismail A, Honkala E. 310 2011. Global oral health inequalities: dental caries task group--research agenda. Advances in 311 Dental Research 23:211-220. DOI: 10.1177/0022034511402016.

312 Sahin AN, Sahin AS, Schwenter F, Sebajang H. 2018. YouTube videos as a source of 313 information on colorectal cancer: what do our patients learn? Journal of Cancer Education 314 (Epub ahead of print). DOI: 10.1007/s13187-018-1422-9.

315 Santiago BM, Valença AM, Vettore MV. 2013. Social capital and dental pain in Brazilian 316 northeast: a multilevel cross-sectional study. BMC Oral Health 13:2. DOI: 10.1186/1472-6831$317 \quad 13-2$.

318 Shatto B, Erwin K. 2017. Teaching millennials and generation Z: bridging the generational 319 divide. Creative Nurse 23:24-28. DOI: 10.1891/1078-4535.23.

320 Statista. 2018. Youtube statistics. Available at https://www.statista.com/topics/2019/youtube/ 321 (accessed 26 September 2018).

322 The United Nations. 2014. Country classification. Available at 323 https://www.un.org/en/development/desa/policy/wesp/wesp_current/2014wesp_country_classific 324 ation.pdf (accessed 21 May 2019).

325 The World Health Organization. 2019. Health statistes and information systems. Available at 326 https://www.who.int/healthinfo/global_burden_disease/about/en/(accessed 27 May 2019).

327 Walthouwer MJ, Oenema A, Lechner L, de Vries H. 2015. Comparing a video and text version 328 of a Web-based computer-tailored intervention for obesity prevention: a randomized controlled 329 trial. Journal of Medical Internet Research 17:e236. DOI: 10.2196/jmir.4083.

330 World Bank Group. 2018. Individuals using the Internet. Available at 331 https://data.worldbank.org/indicator/IT.NET.USER.ZS (accessed 05 December 2018). 


\section{Table $\mathbf{1}$ (on next page)}

Table 1

Table 1. Disability-adjusted life years (DALYs) for countries, country groups and years. Note that there were no significant statistical differences between DALYs of developed and developing countries over time (similar lower superscript letters, Mann-Whitney $P>0.05$ ) 
1 Table 1. Disability-adjusted life years (DALYs) for countries, country groups and years. Note that there 2 were no significant statistical differences between DALYs of developed and developing countries over time 3 (similar lower superscript letters, Mann-Whitney $P>0.05$ )

\begin{tabular}{lcccccccccc}
\hline & \multicolumn{10}{c}{ Years } \\
Countries & $\mathbf{2 0 0 8}$ & $\mathbf{2 0 0 9}$ & $\mathbf{2 0 1 0}$ & $\mathbf{2 0 1 1}$ & $\mathbf{2 0 1 2}$ & $\mathbf{2 0 1 3}$ & $\mathbf{2 0 1 4}$ & $\mathbf{2 0 1 5}$ & $\mathbf{2 0 1 6}$ & $\mathbf{2 0 1 7}$ \\
\hline Australia & 24.67 & 24.62 & 24.60 & 24.68 & 24.91 & 25.27 & 25.74 & 26.31 & 26.95 & 27.64 \\
Chile & 35.09 & 34.80 & 34.65 & 34.60 & 34.58 & 34.56 & 34.54 & 34.54 & 34.55 & 34.57 \\
Japan & 23.59 & 23.33 & 23.19 & 23.15 & 23.10 & 23.06 & 23.04 & 23.02 & 23.04 & 23.09 \\
UK & 36.43 & 36.38 & 36.33 & 36.27 & 36.19 & 36.12 & 36.06 & 36.00 & 35.94 & 35.88 \\
USA & 21.94 & 21.98 & 22.05 & 22.19 & 22.42 & 22.72 & 23.08 & 23.48 & 23.93 & 24.41 \\
\hline Developed countries & $\mathbf{2 8 . 3 4}^{\mathbf{a}}$ & $\mathbf{2 8 . 2 2}^{\mathbf{a}}$ & $\mathbf{2 8 . 1 6}^{\mathbf{a}}$ & $\mathbf{2 8 . 1 8}^{\text {a }}$ & $\mathbf{2 8 . 2 4}^{\mathbf{a}}$ & $\mathbf{2 8 . 3 5}^{\mathbf{a}}$ & $\mathbf{2 8 . 4 9}^{\mathbf{a}}$ & $\mathbf{2 8 . 6 7}^{\mathbf{a}}$ & $\mathbf{2 8 . 8 8 ^ { \mathbf { a } }}$ & $\mathbf{2 9 . 1 2}^{\mathbf{a}}$ \\
\hline Brazil & 32.05 & 32.01 & 31.99 & 32.01 & 32.02 & 32.03 & 32.05 & 32.09 & 32.14 & 32.19 \\
Mexico & 25.99 & 25.76 & 25.64 & 25.60 & 25.56 & 25.53 & 25.51 & 25.49 & 25.48 & 25.48 \\
Russia & 39.86 & 39.67 & 39.45 & 39.21 & 38.93 & 38.64 & 38.35 & 38.05 & 37.76 & 37.49 \\
Saudi Arabia & 21.95 & 22.10 & 22.22 & 22.32 & 22.41 & 22.48 & 22.56 & 22.65 & 22.73 & 22.80 \\
South Africa & 15.78 & 15.67 & 15.62 & 15.60 & 15.58 & 15.55 & 15.52 & 15.50 & 15.49 & 15.50 \\
\hline Developing countries & $\mathbf{2 7 . 1 3}^{\mathbf{a}}$ & $\mathbf{2 7 . 0 4}$ & $\mathbf{2 6 . 9 8}^{\mathbf{a}}$ & $\mathbf{2 6 . 9 5}^{\mathbf{a}}$ & $\mathbf{2 6 . 9 0}^{\mathbf{a}}$ & $\mathbf{2 6 . 8 5}^{\mathbf{a}}$ & $\mathbf{2 6 . 8 0}^{\mathbf{a}}$ & $\mathbf{2 6 . 7 6}^{\mathbf{a}}$ & $\mathbf{2 6 . 7 2}^{\mathbf{a}}$ & $\mathbf{2 6 . 6 9}^{\mathbf{a}}$ \\
\hline & & & & & & & & & &
\end{tabular}




\section{Table 2 (on next page)}

Table 2

Table 2. Mean ( \pm SD) of toothache-related searches performed in Googleand YouTubefor users from developed and developing countries in different periods. Upper superscript letters indicate significant statistical differences between country groups considering the same engine search. Lower superscript letters indicate significant statistical differences between periods considering the same country group and engine search 
1 Table 2. Mean $( \pm \mathrm{SD})$ of toothache-related searches performed in Google and YouTube for users from 2 developed and developing countries in different periods. Upper superscript letters indicate significant 3 statistical differences between country groups considering the same engine search. Lower superscript letters 4 indicate significant statistical differences between periods considering the same country group and engine 5 search.

\begin{tabular}{ccccc}
\hline & \multicolumn{2}{c}{ Google searches } & \multicolumn{2}{c}{ YouTube searches } \\
\cline { 2 - 5 } Period & $\begin{array}{c}\text { Developed } \\
\text { countries }\end{array}$ & $\begin{array}{c}\text { Developing } \\
\text { countries }\end{array}$ & $\begin{array}{c}\text { Developed } \\
\text { countries }\end{array}$ & $\begin{array}{c}\text { Developing } \\
\text { countries }\end{array}$ \\
\hline $\begin{array}{c}\text { Whole period } \\
(\mathbf{2 0 0 8 - 2 0 1 7})\end{array}$ & $61.74 \pm 5.80^{\mathrm{Aa}}$ & $46.79 \pm 20.35^{\mathrm{Ba}}$ & $16.01 \pm 5.56^{\mathrm{Aa}}$ & $10.91 \pm 5.88^{\mathrm{Ba}}$ \\
\hline $\begin{array}{c}\text { Last 5 ys. } \\
(\mathbf{2 0 1 3 - 2 0 1 7 )}\end{array}$ & $77.16 \pm 3.52^{\mathrm{Ab}}$ & $63.77 \pm 11.75^{\mathrm{Bab}}$ & $19.37 \pm 6.19^{\mathrm{Aa}}$ & $14.95 \pm 5.97^{\mathrm{Aa}}$ \\
\hline $\begin{array}{c}\text { Last 4 ys. } \\
(\mathbf{2 0 1 4 - 2 0 1 7 )}\end{array}$ & $79.91 \pm 2.84^{\mathrm{Ab}}$ & $67.92 \pm 8.32^{\mathrm{Bb}}$ & $19.81 \pm 7.06^{\mathrm{Aa}}$ & $15.94 \pm 6.40^{\mathrm{Aa}}$ \\
\hline $\begin{array}{c}\text { Last 3 ys. } \\
(\mathbf{2 0 1 5 - 2 0 1 7 )}\end{array}$ & $81.86 \pm 2.91^{\mathrm{Ab}}$ & $71.43 \pm 5.48^{\mathrm{Bab}}$ & $21.42 \pm 7.69^{\mathrm{Aa}}$ & $16.71 \pm 7.61^{\mathrm{Aa}}$ \\
\hline $\begin{array}{c}\text { Last 2 ys. } \\
(\mathbf{2 0 1 6 - 2 0 1 7 )}\end{array}$ & $83.01 \pm 4.64^{\mathrm{Aab}}$ & $73.29 \pm 6.27^{\mathrm{Aab}}$ & $23.70 \pm 9.33^{\mathrm{Aa}}$ & $18.89 \pm 9.36^{\mathrm{Aa}}$ \\
\hline $\begin{array}{c}\text { Last year } \\
(\mathbf{2 0 1 7})\end{array}$ & $87.84 \pm 2.50^{\mathrm{Ab}}$ & $77.78 \pm 3.17^{\mathrm{Ab}}$ & $30.30 \pm 19.16^{\mathrm{Aa}}$ & $25.50 \pm 13.47^{\mathrm{Ba}}$ \\
\hline
\end{tabular}

6

7

8 
Table 3 (on next page)

Table 3

Table 3. ARIMA model fit statistics 
1 Table 3. ARIMA model fit statistics

2

\begin{tabular}{|c|c|c|c|c|c|c|c|c|}
\hline $\begin{array}{l}\text { Country group } \\
\text { Web platform } \\
\text { ARIMA model }\end{array}$ & $\begin{array}{c}\text { Normalized } \\
\text { BIC }\end{array}$ & MAPE & $\begin{array}{l}\text { Ljung- } \\
\text { Box }\end{array}$ & Model parts & Lag & Estimate & SE & $p$ \\
\hline \multicolumn{9}{|l|}{$\begin{array}{l}\text { Developed } \\
\text { Countries }\end{array}$} \\
\hline \multicolumn{9}{|l|}{ Google } \\
\hline \multirow[t]{2}{*}{$(0,1,1)(0,1,1)$} & 2.42 & 3.91 & 0.77 & MA & Lag 1 & 0.60 & 0.07 & $<0.01$ \\
\hline & & & & MA, Seasonal & Lag 1 & 0.53 & 0.08 & $<0.01$ \\
\hline \multicolumn{9}{|l|}{$\begin{array}{l}\text { Developed } \\
\text { Countries }\end{array}$} \\
\hline \multicolumn{9}{|l|}{ YouTube } \\
\hline$(0,0,0)(0,0,0)$ & 4.19 & 113.96 & 0.83 & Constant & & 13.36 & 0.70 & $<0.01$ \\
\hline \multicolumn{9}{|l|}{$\begin{array}{c}\text { Developing } \\
\text { Countries }\end{array}$} \\
\hline \multicolumn{9}{|l|}{ Google } \\
\hline \multirow[t]{2}{*}{$(0,0,0)(1,1,0)$} & 2.89 & 6.50 & 0.40 & Constant & & 0.16 & 0.01 & $<0.01$ \\
\hline & & & & AR, Seasonal & Lag 1 & -0.48 & 0.08 & $<0.01$ \\
\hline \multicolumn{9}{|l|}{$\begin{array}{c}\text { Developing } \\
\text { Countries }\end{array}$} \\
\hline \multicolumn{9}{|l|}{ YouTube } \\
\hline$(0,1,1)(0,0,0)$ & 2.49 & 32.54 & 0.52 & Constant & & 0.10 & 0.01 & $<0.01$ \\
\hline & & & & MA & Lag 1 & 1.00 & 0.04 & $<0.01$ \\
\hline
\end{tabular}

3

4

5

6 
Figure 1

Relative Search Volume for toothache-related searches

Relative Search Volume for toothache-related searches in developed countries in Web (A), developing countries in Web (B), developed countries in YouTube (C) and developing countries in YouTube (D)

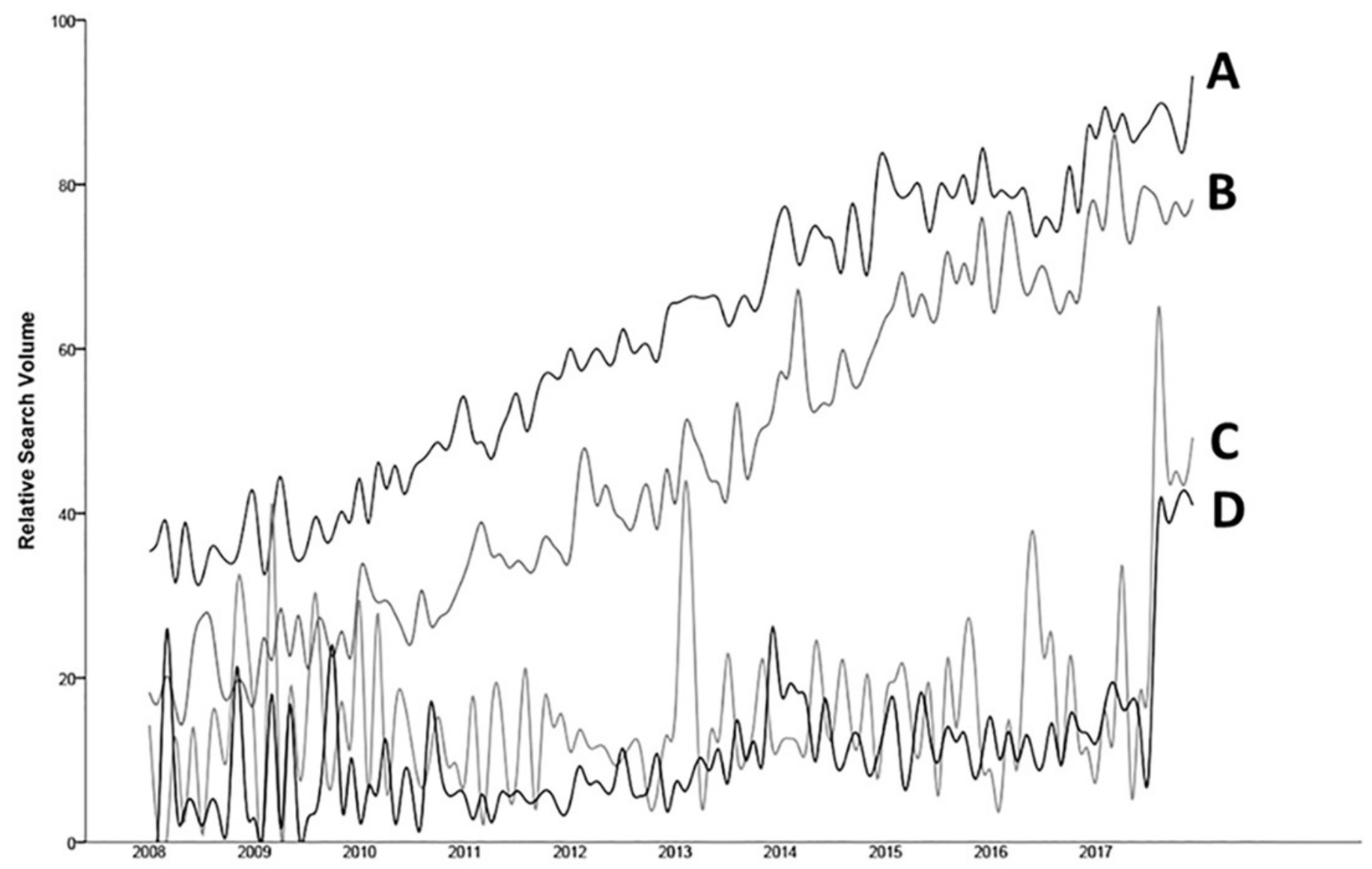


Figure 2

Autocorrelation (ACF) and Partial autocorrelation (Partial ACF) plots for the monthly variation of RSV toothache

Autocorrelation (ACF) and Partial autocorrelation (Partial ACF) plots for the monthly variation of RSV toothache. (A/B) developed countries in Web, (C/D) developed countries in YouTube, $(\mathrm{E} / \mathrm{F})$ developing countries in Web, $(\mathrm{G} / \mathrm{H})$ developing countries in YouTube

A

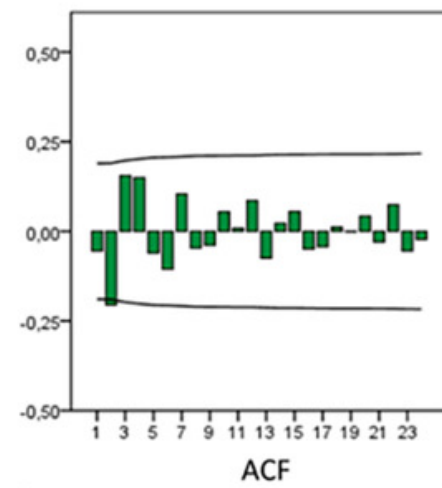

C

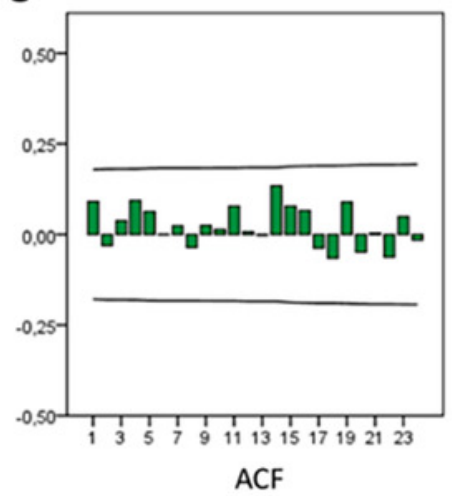

B

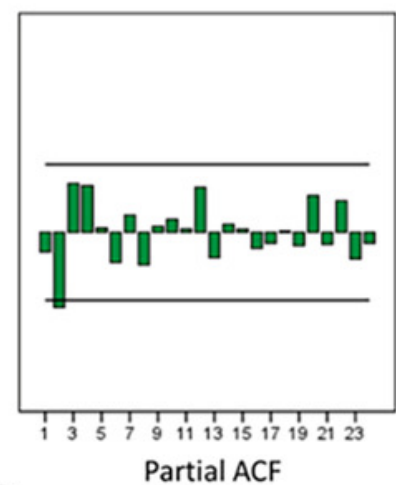

D

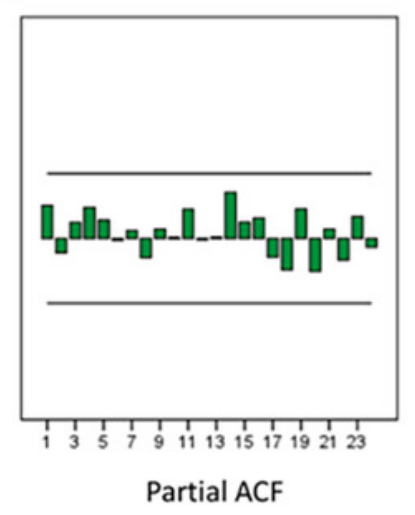

E

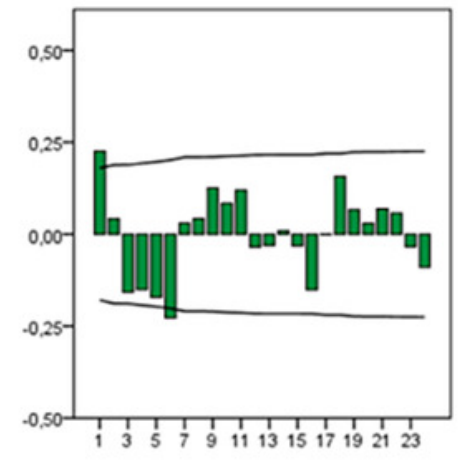

ACF

G

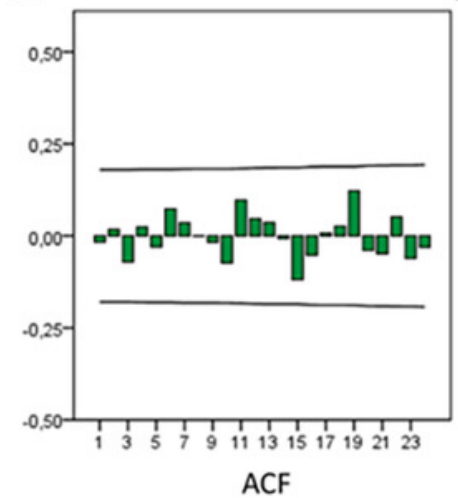

F

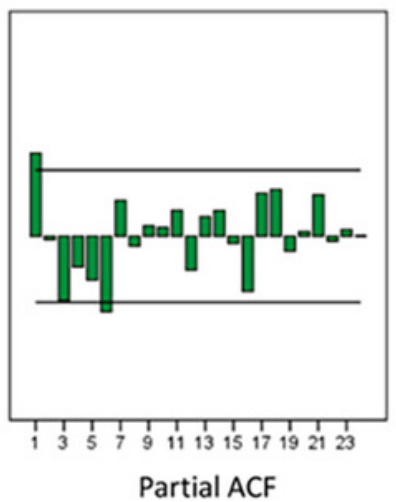

H

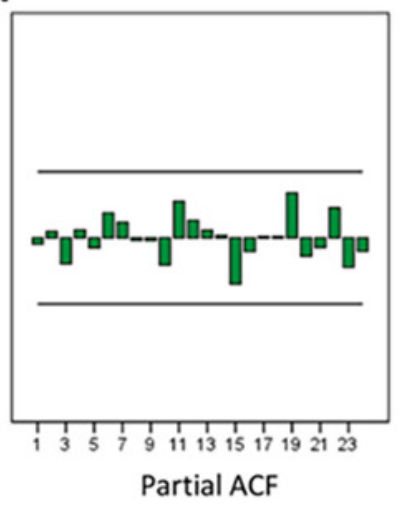


Figure 3

Predictive charts demonstrate the variation of RSV

Predictive charts demonstrate the variation of RSV in developed countries in Web (A), developed countries in YouTube (B), developing countries in Web (C) and developing countries in YouTube (D). Note that RSVs presented after 2018 represent 12-month predictive values 


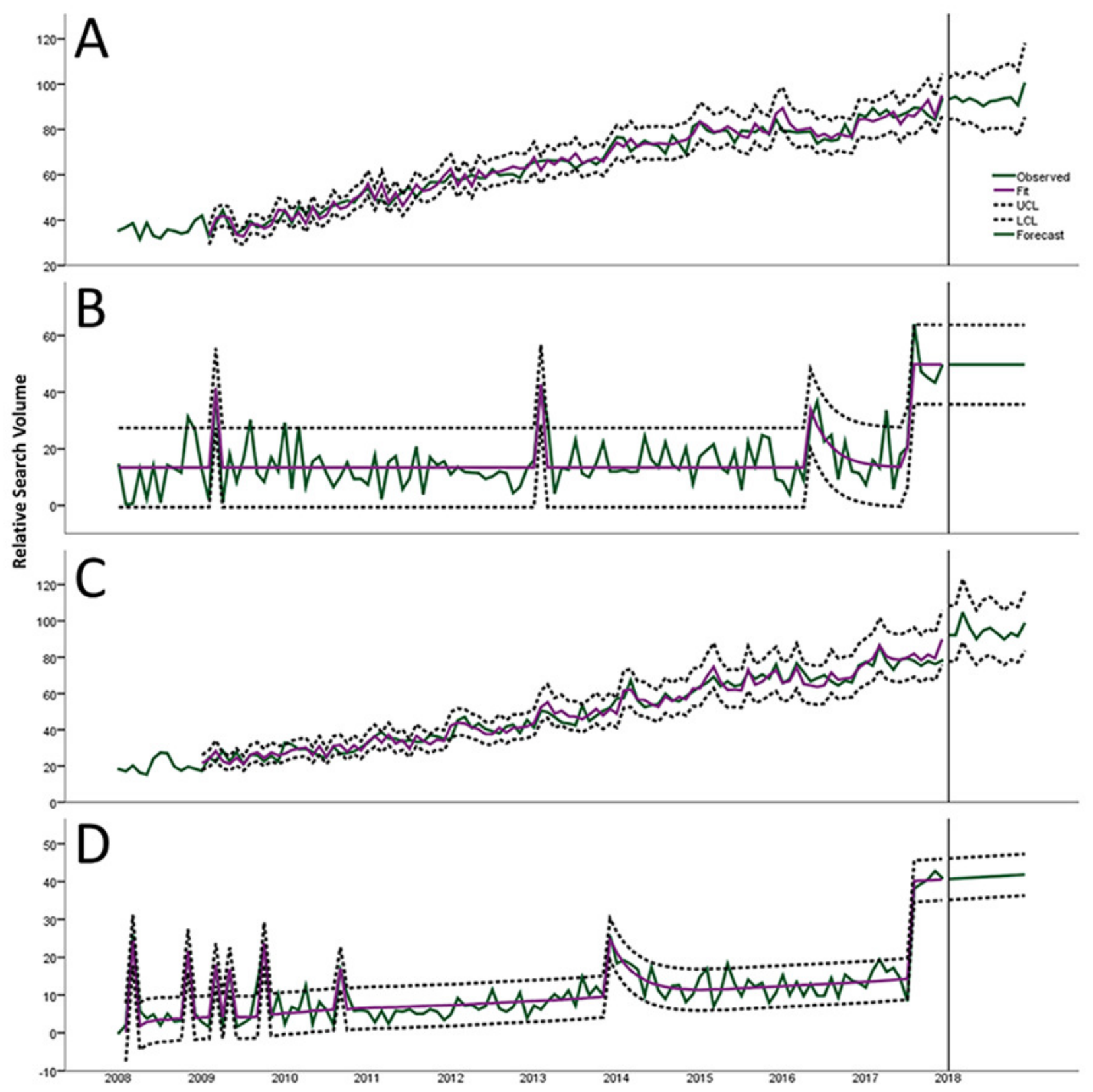


Figure 4

Ratio between YouTube and Web searches

Ratio between YouTube and Web searches for developed countries (A) and developing countries (B)
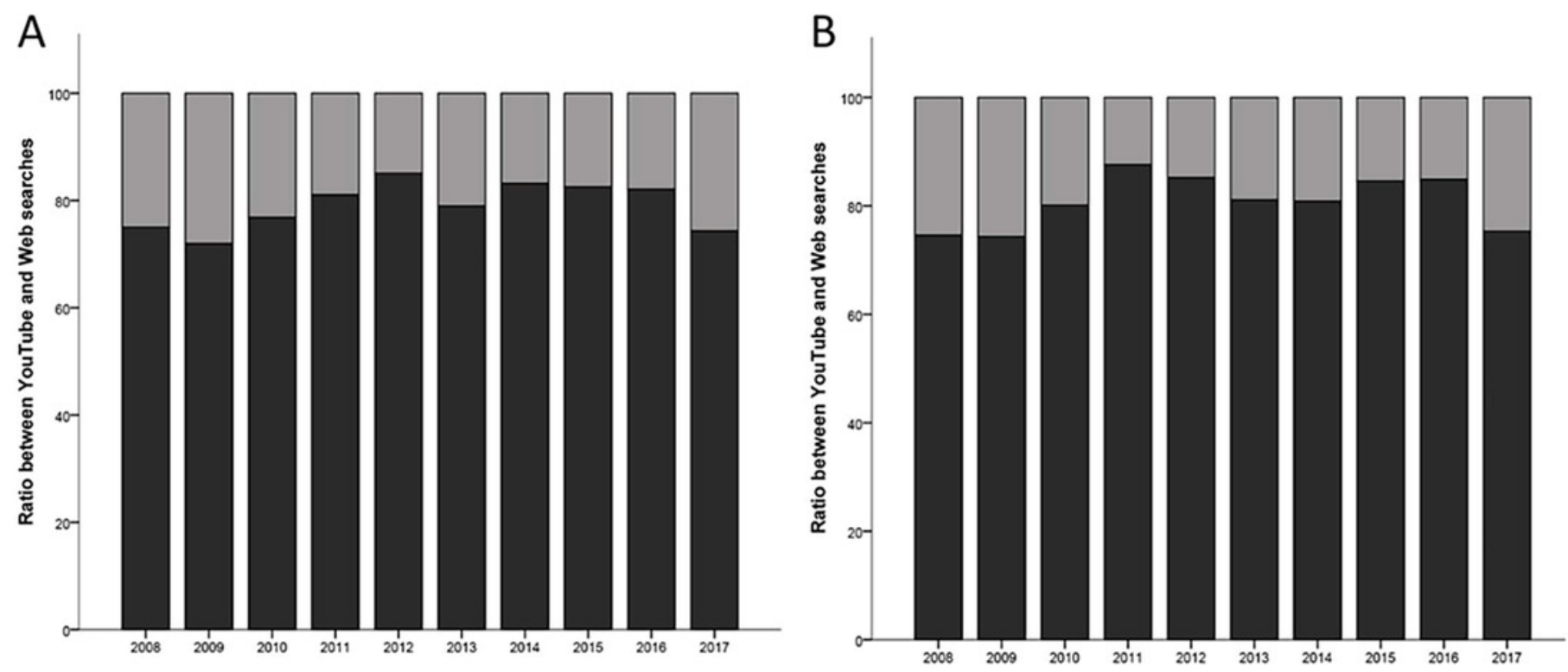